\title{
The Paradox of Social Ties after the ICT Revolution: A Second-Order Observation
}

\author{
Saburo Akahori \\ Department of Sociology, \\ Tokyo Woman's Christian University \\ 2-6-1 Zempukuji, Suginami-Ku, Tokyo, Japan \\ akahori@lab.twcu.ac.jp
}

\begin{abstract}
This paper explores what kinds of distinctions are used when the change of social systems is observed. We seek a more appropriate description of society in the face of online relationships. This task will be carried out through a case study of Japan. In recent years, the significance of social ties has repeatedly been emphasized in Japan. One example is the frequency of use of the Japanese word kizuna which means "bond". It sounds odd because conventionally kizuna indicates intimate, continuous relationships, not temporary relationships. Even though the word kizuna means strong ties, now it also implies weak ties. Here we examine the reason why the strange usage of the word kizuna has become acceptable. We focus on topics related to the observation of social ties. On one hand, connections between strangers are becoming more imaginable due to the recent change of communication media after the ICT revolution, especially the rise of so-called social media. On the other hand, social relationships between strangers through social media have been seen as paradoxical in recent years. We assume that this enables us to accept the strange usage of the word kizuna. Then we describe the phenomenon by using other distinctions. For example, we adopt the classic sociological distinction between personal and impersonal. Social relationships between strangers seen in social media can be categorized not as impersonal but as personal; however they are sharply distinguished from social ties in traditional communities or intimate relationships. It can be understood as a variant of "doubling of reality" in Niklas Luhmann's theory of mass media. This can also be a clue to rethink modernity or to rethink solidarity among heterogeneous people. After the ICT revolution, observations on communications or social ties tend to be paradoxical. However, the recent changes can be seen from the meta-level by using other distinctions. Sociologists have to unfold the paradox and describe them through more appropriate frameworks.
\end{abstract}

Keywords: social bonds, social media, systems theory, Niklas Luhmann 


\section{Introduction}

Recent sociological research, especially within these last two decades, has been reporting the disintegrative tendencies of society under various expressions, such as the collapse of communities, the breakup of the modern family, the transformation of intimacy, individualization, the decline of social capital, and so on. This paper deals with topics related to these tendencies, however we are not going to repeat previous research. Instead, we will try to observe how such trends are observed. In other words, what we are going to do in this paper is a second-order observation of the trendobservers.

By using the term "second-order observation", we intend to apply the idea of Heinz von Foerster, the theory of observation of observing systems, to the sociological field. In the context of Niklas Luhmann's sociological systems theory, social systems, which are defined as chaining processes of communication (or, communicative events), are also counted among observers (or, observing systems). Social systems' observation is abstractly defined as an operation consisting of two components: distinction and indication. The importance of the distinction used in communication processes is emphasized as a basis of meaning construction, and moreover, a certain kind of "blind spot" for social systems (Luhmann 1997: 426). Therefore, in this context, second-order observation to social systems means, to observe the observation carried out by social systems (or, process of communication) in regard to distinctions.

The reason why we are going to take this approach is because, as a sociological observation, we would like to gain a better understanding of society beyond moral judgment, or beyond the blind spot of social systems, for example, the distinction between good and bad.

This task is carried out through a case study of Japan after the March 2011 disasters (earthquake, tsunami and nuclear disasters of East Japan) because there we can find an example of a strange description of social ties. After reviewing the case, we move on to analyze why such expressions become acceptable. That is the main research question of this paper. To answer this question, we focus on recent changes of communication media, especially the rise of so-called social media after the ICT revolution. Along with this transformation, emergence of new types of social ties has been reported. We focus on such observations of social ties in relation to the ICT revolution from a second-order perspective. By this, we seek a better tool to observe the social world. 


\section{Case Study: An Odd Expression of Social Ties Emerged in Japan}

Then we pick up, as a case study, an example of how social ties are described. The case is broadly found in recent discourses of Japanese mass media. On the 11th of March, 2011 Japan was struck by a catastrophic earthquake and devastating tsunami, and on the following day, the first hydrogen explosion occurred in the Fukushima Dai-ichi nuclear power plant. The series of disasters after 3/11/2011 was officially named "the Great East japan Earthquake Disaster". Japan has not recovered from it yet, although a few years have passed. Meanwhile, many apparent changes have been observed in Japan. In the following, especially, we pay attention to the observed changes in Japanese mass media's discourses on social ties, at the level of second-order observation.

\subsection{Pre-2011 Context}

Before the 2011 disasters, as mentioned above, the disintegrative tendencies of society had already been regarded as questionable in Japan. It is not only inside sociology. These tendencies have been propagandized extensively in leading mass media. For example, in 2010, NHK (Nihon Hōsō Kyōkai, Japan Broadcasting Corporation) produced a series of documentary TV programs entitled Muen-Shakai (無縁社会; disconnected society), which is a newly created word in Japanese ${ }^{(1)}$. These programs dealt with the destructive trends in Japan, such as the rise of one-person households, the social isolation of single men and women, the problem of solitary death (NHK 2012). Japanese people often use an idiomatic expression "kihaku (稀薄)" meaning “thinner" (a literal translation) to describe the recent trends in social relationships of the Japanese people's disconnected society. Accompanied by this peculiar expression, traditional social ties, for example blood ties, territorial bonds, and intimate relationships, have been praised in Japanese mass media.

\subsection{Post-2011 Context}

After the 2011 calamity, Japanese mass media emphasized the significance of social ties all the more in the context of sharing the hardship of the victims with the rest of the population in order to support them. In this extensive campaign, the Japanese word kizuna (絆，きずな) which means “bond” has frequently been used as a metaphor for social ties and it has become a cliché in Japan (figure 1). 


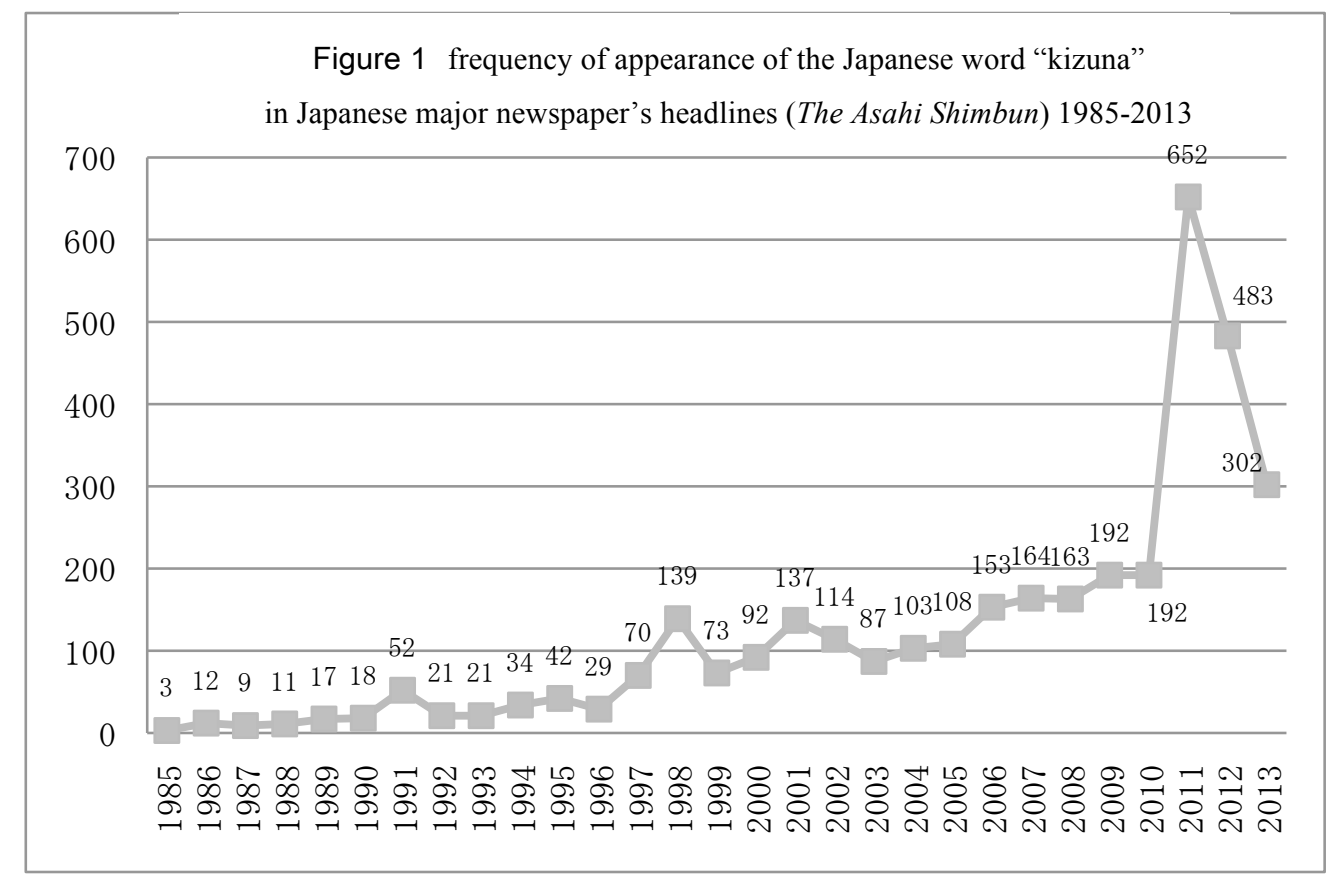

Source of data: The Asahi Shimbun's online database "Kikuzo II Visual” (https://database.asahi.com/library2/)

Some people regard this phenomenon as a regression to traditional social ties. However, such an opinion seems to be incorrect. In post 3/11/2011 Japan, the word kizuna is not always used as a symbol of intimate relationships. Rather, it is often used as a symbol of the solidarity among people, not only inside Japan but also abroad. For example, a press release issued on April 11th 2011, exactly one month after the outbreak of the disasters, was entitled "Kizuna: The Bonds of Friendship" (2). The message was given by Naoto Kan, the Prime Minister of Japan at the time. In the message, Kan expressed his gratitude for the support from overseas in response to the disasters in Japan. Although the Japanese word kizuna is not usually used to indicate international cooperation or disaster assistance, in this case it was used as a symbol of Kan's political belief which already existed before the disasters.

\subsection{Paradox of kizuna}

Here we briefly demonstrate why we regard the usage of kizuna as paradoxical. In social network theory, social capital is one of the most important concepts. Social capital is usually classified into the bonding type and the bridging type (Putnam 2000). The bonding type of social capital is found in social networks of homogeneous individuals and is fostered in continuous relationships. On the contrary, the bridging type of social capital is found in social networks of heterogeneous individuals (Figure 2). 
Conventionally kizuna indicates relationships seen in primary groups such as blood ties, territorial bonds and intimate relationships and it is not used to express heterogeneous and temporary relationships, or "weak ties" as defined in "The Strength of Weak Ties" by Mark Granovetter (1973). That is to say that kizuna is the word which indicates the bonding type of social capital ${ }^{(3)}$. Nevertheless, after the March 2011 disasters, the word kizuna has come to be used to indicate relationships between strangers or passersby, or the bridging type of social capital. The word kizuna originally means strong ties or "thick" relationships, however, now kizuna is a cliché after March 2011 disaster also implying weak ties or "thin" relationships. In other words, it is a paradoxical description of relationships because in the expression opposite things are regarded as identical (Figure 3).

Then we ask: why has the odd expression recently become acceptable? To answer this question, we focus on the observations of social ties in relation to the ICT revolution.
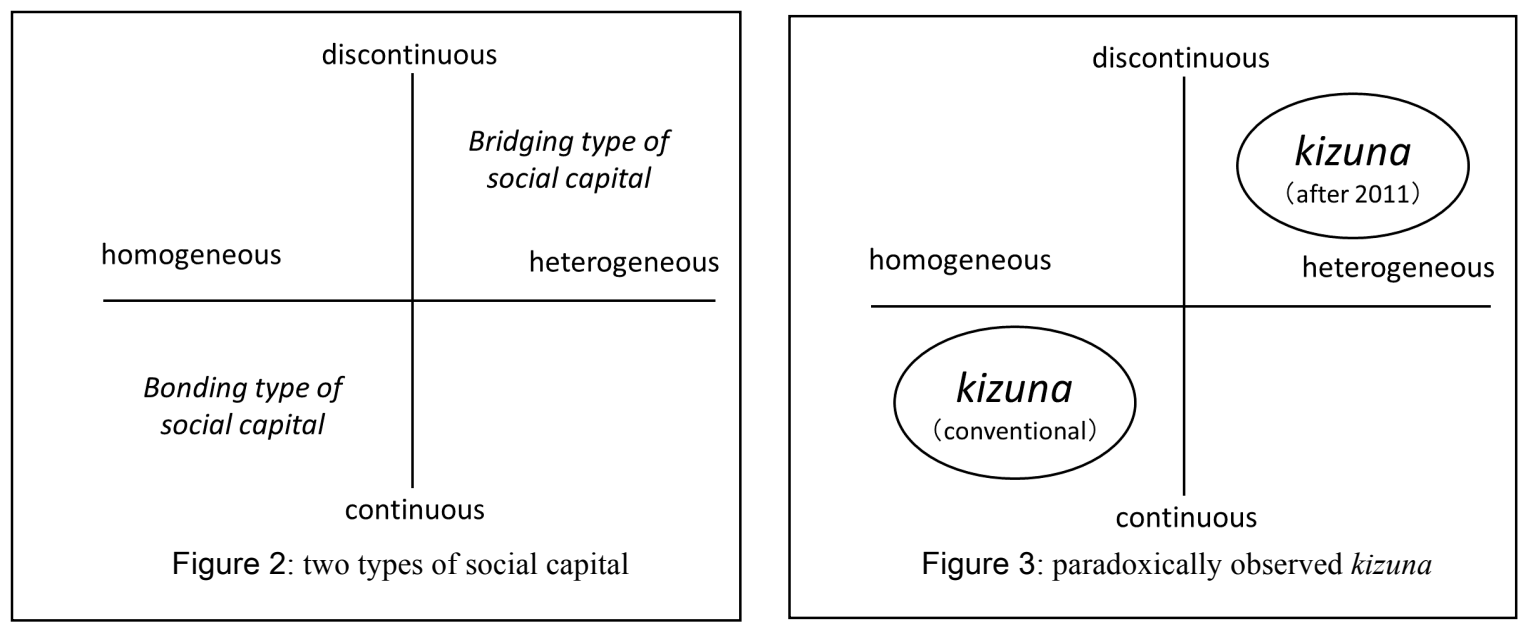

\section{Observed Changes of Social Ties after the ICT Revolution}

What we are going to examine here is not whether a new type of kizuna (social bonds) has emerged, but why the odd usage of the word was become acceptable. We can no longer assume that Japanese nationals are integrated through the pseudo-family systems of the past. What we pay attention to is the observation of social ties after the ICT revolution.

The reasons why we focus on the topics after the ICT revolution are as follows: First, connections between strangers have become more and more imaginable by the recent changes of communication media after the ICT revolution, especially by the rise of socalled social media ${ }^{(4)}$, such as anonymous BBS (bulletin board system), blogs, SNS, 
video hosting services, social games and so on. Particularly in Japan, since the end of the 20th century, many empirical examples of social ties related to social media have been reported such as off-line meeting (meeting online friends IRL), deai-kei site (出会い系サイト; Internet-based encounter sites), internet dating, Q\&A sites, online video game, social network game on mobile devices etc. Second, at least in Japan, the characteristics of communication or social relationships between strangers or passersby through social media platforms have been seen as deviant or underground since their beginning.

Social media mentioned above do not always connect heterogeneous individuals. Among others, SNS has been regarded to connect rather homogeneous individuals, as Boyd and Ellison (2007) demonstrated. However, here we focus on the relationships between strangers or heterogeneous individuals because in Japan the emergence of a peculiar type of trust or reciprocity between strangers has been reported by some writers and scholars in relation with the ICT revolution or the rise of social media.

For example, a freelance journalist Tetsuya Shibui reported on "Internet group suicide”, Netto shinju (ネット心中) in Japanese, by interviewing several people who attempted suicides (Shibui 2004). What "Internet group suicide" refers to is a suicide committed by two or more individuals who get acquainted with each other through socalled suicide sites, or anonymous BBS. According to Shibui (2004), one of the interviewees said that he tried to commit "Internet group suicide" not because he felt lonely but he wanted to die easier and more surely than committing suicide alone. In that case, each volunteer of "Internet group suicide" cooperate with each other to commit suicide ${ }^{(5)}$.

An international comparative survey on MMORPG (Massively Multiplayer Online Role Playing Game) shows another example of observed changing social ties (for example: Kobayashi and Ikeda 2005, Shimura 2005). In MMORPGs, hundreds or thousands of players connect to one server and cooperate with each other in playing the video game. Through analyzing the data of the survey, Kobayashi and Ikeda (2005) concluded that online video games can cultivate general reciprocity among heterogeneous individuals ${ }^{(6)}$.

The above mentioned phenomena are the tip of the iceberg. In addition, many cooperative behaviors between strangers have been reported in connection with the development of social media. In other words, it is reported that social media enable us to connect with strangers and cooperate with each other. Namely, in these cases, "improbabilities of communication" are reduced by social media. Therefore we can understand social media in the meaning of "communication media" in Niklas Luhmann's theory (Luhmann 1997). 


\section{An Attempt of Second-Order Observation}

In this paper we do not ask whether trust or reciprocity has emerged in the relationships between complete strangers or heterogeneous individuals through social media. What we would like to illustrate here, in relation to the rise of social media, is the fact that the emergence of social ties between complete strangers has been observed by society as an observer (in Niklas Luhmann's sense).

Then we will move on to explore appropriate ways of describing social ties after the ICT revolution. Our suggestion is that cooperative activities between heterogeneous individuals through social media should not be observed by conventional distinctions, such as virtual and real, online and offline, cyberspace and real life, or, the Japanese mass media's distinctions of strong and weak, "thick" and "thin".

\subsection{Personal or Impersonal?}

By using the sociological distinction between embedded and disembedded (Granovetter 1985), social ties between strangers can be understood as disembedded because the disembeddedness is undoubtedly one of the essential elements of modernity. Then we adopt the classic sociological distinction between personal and impersonal (as is the case with the distinction between persönlich and sachlich in Max Weber's theory of bureaucracy). As a result, we can classify social relationships in a two dimensional coordinate plane (Figure 4).

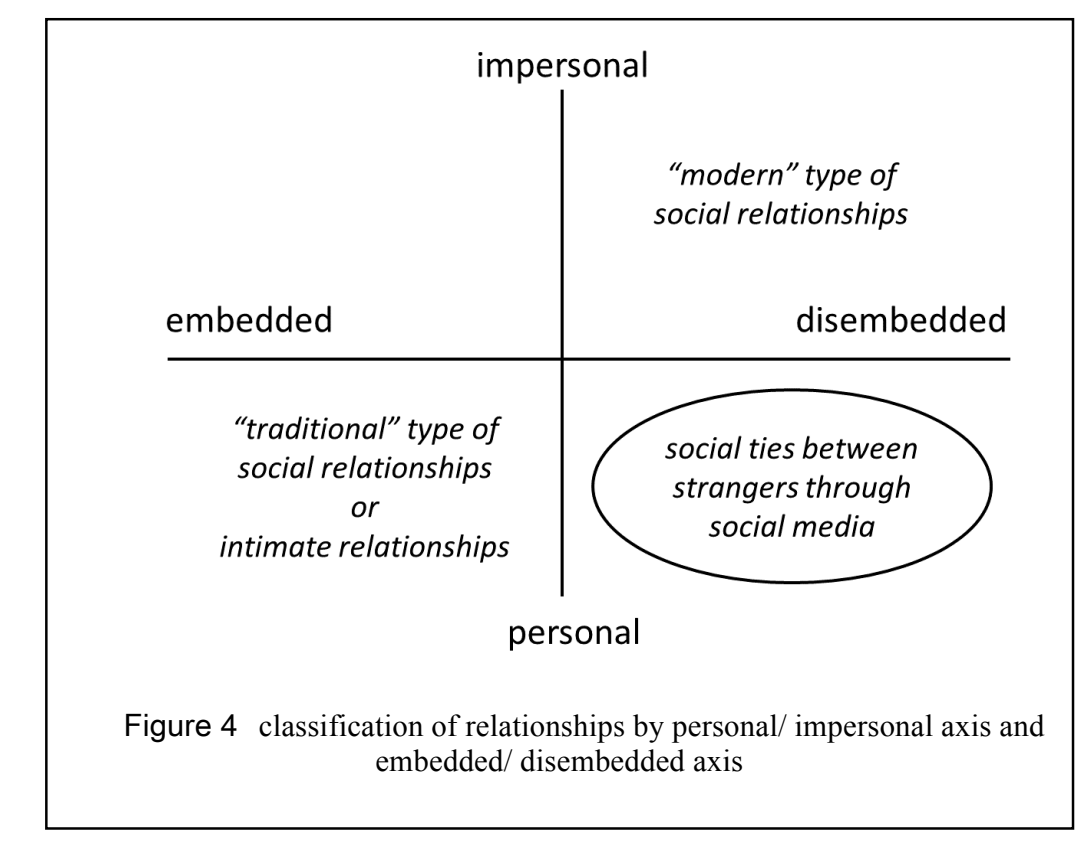


Social relationships between strangers seen in social media are often categorized as impersonal because anonymity (including the use of pseudonyms) is observed there. However, some empirical studies, for example studies on MMORPGs, anonymous BBS, allow us to interpret the relationships between strangers seen in social media not as impersonal but as personal because the use of pseudonyms does not directly mean elimination of personas. Participants in communication through a particular social media can easily construct their personas independently from their "original" personas through the communication process itself. This corresponds with the fact that social networks of individuals who interact through social media are often called "communities". For example, Howard Rheingold's The Virtual Community (1993) or what Ken'ichi Ikeda called "Internet community" or "online community" (Kobayashi and Ikeda 2005).

Niklas Luhmann also observes what he called "intimate relationships" by adopting the distinction between personal and impersonal.

\begin{abstract}
„Above all, at the communicative level, there are rules or codes which prescribe that in certain social situations one must be receptive in principle to everything about another person, must refrain from displaying indifference towards what the other finds of great personal relevance and in turn must leave no question unanswered, even if and especially when this centres on matters of a personal nature." (Luhmann 1982=1986: 13-14)
\end{abstract}

However social ties between complete strangers through social media are sharply distinguished from social ties in traditional communities or intimate relationships. In the examples of communication mediated by social media mentioned above, rules or codes are not identical. As Shimura reported, sometimes MMORPG players construct intimate relationships with another player, but personal information "offline" is not regarded as very important in the online relationship (Shimura 2005). From this viewpoint, what is going on through social media can be understood as re-personalization ${ }^{(7)}$. This can also be a clue toward rethinking modernity because the process of modernization has normally been regarded as impersonalization in sociology.

\title{
4.2 Social Media: Only Limited Part of Society?
}

One may suspect that what is occurring through social media is only affecting a very limited part of society. Our opinion differs. It is true that CMC (Computer Mediated Communication) has often been categorized as unreal or "virtual" (8). However, according to Luhmann's sociological systems theory, society is defined as a comprehensive system which consists of communication. We should accept this theory, and thus communication processes through social media cannot occur outside society. 
Then we move on to discuss whether it can be regarded as a subsystem differentiated from society. We may say the differentiation of societal system through social media can be understood as a variant of "doubling of reality" as Luhmann had demonstrated in his theory of mass media (Luhmann 1995). As for social media, participants of communication through social media can foster "online" personas. In the meaning of crossing between two entities, it is parallel with the function of entertainment, which is one of three segments of the system of mass media in Luhmann's theory (Figure 5,6). It is unclear that communication through social media can be categorized as an independent subsystem or a functional system of society; however we can safely say that it enables us to cross the boundary between two personas.
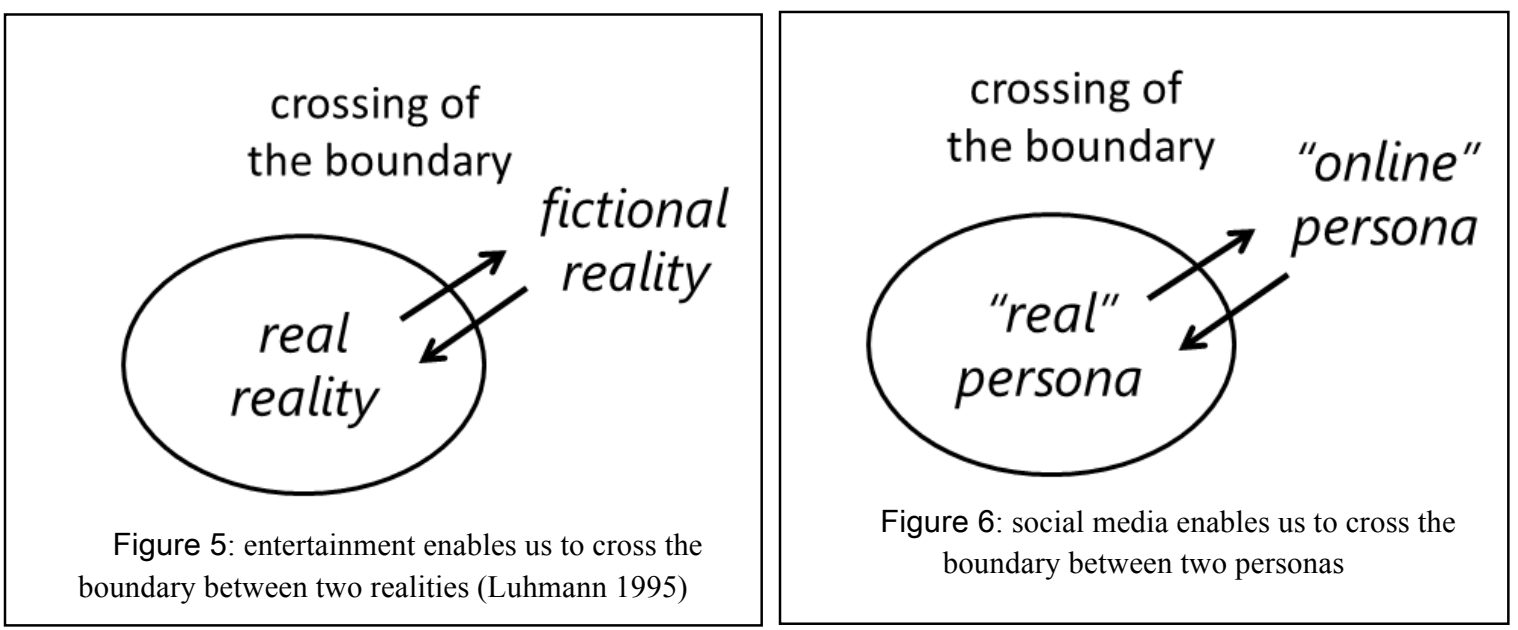

Regarding the characteristics of social relationships through social media, we find that they are very similar to social relationships in the theory of urbanism proposed by Louis Wirth (1938). With reference to Wirth's theory, urbanization as a way of life ${ }^{(9)}$ is not found only in cities. It also spreads to larger area of society, to the remotest area of the world. Correspondingly, the lifestyle created through social media cannot be limited to only "online" worlds. It is diffused throughout the whole of society. From this point of view, we can demonstrate the reason why the above-mentioned odd usage of the word kizuna has become acceptable in public discourse. It is because the lifestyles developed in social media are widespread throughout society.

In regard to the rise of social media and the rapid change of communication media, a kind of "plausibility structure" (in Peter Berger's sense) related to social ties has been emerging. As for Niklas Luhmann, he discussed the relationship between differentiation of society and "evolution of ideas" (Ideenevolution) in his series of books entitled 
Gesellschaftsstruktur und Semantik (Structure of Society and Semantics). The same may be said for the change of communication media after the ICT revolution.

\section{Conclusion}

In this paper we have raised the question of why the strange descriptions of social ties have become acceptable. To answer this question, we paid attention to the ways of describing social ties after the ICT revolution. In these observations, it has been reported that cooperative behaviors between strangers have become possible through social media platforms in the broad sense of the word. We concluded that the reason why the paradoxical expressions of social ties have become acceptable is because the way of observing social relationships have been changing due to the development of social media.

Based on the trend of individualization and the rise of social media, observations on communications or social ties tend to become more and more complex. Therefore the recent changes in both communication media and social relationships should be seen from a meta-level perspective. Sociologists should not be satisfied with paradoxical expressions such as "The Strength of Weak Ties". To unfold the paradox, we need second-order observations. In other words, we have to describe complex social phenomena through more appropriate sociological frameworks.

Moreover, due to the impact of radical changes in communication media, the concept of modernity has also been questioned. Both the distinction between embedded and disembedded and the distinction between personal and impersonal are closely related to the concept of modernity. Adding that, let us introduce another distinction, that is, the distinction between Western and non-Western. In the Western context, connection through social media tends to be regarded as an extension of "offline" relationships. However, as we have already mentioned above, a lot of empirical examples of new social ties beyond the distinction between online and offline have been reported. These phenomena are seen worldwide but at least some of them start in East Asia. Asia, especially East Asia, may be regarded as homogeneous rather than heterogeneous compared with rest of the world. One may suspect that such phenomena are possible only in homogeneous world. However, even if we accept this point of view, we can foresee the idea of solidarity suitable for globalizing era, that is, the personal connection between heterogeneous strangers.

After all, in accordance with the change of communication media, we need to reexamine the fundamental concepts of sociology, such as social ties, social bonds, solidarity, community, and so on. 


\section{Notes}

(1) As for an explanation on Muen-Shakai written in English, see Taylor (2012).

(2) Source: http://www.kantei.go.jp/foreign/kan/statement/201104/11kizuna_e.html

(3) The word kizuna had been used as a metaphor of Internet connecting relationships before 2011. However, it was used to indicate bonding type of social capital. For example, see the title of Miyata (2005).

(4) In this paper we consider ICT revolution including so-called "social media revolution".

(5) In many cases of "Internet group suicide" at the time, they tried to commit suicide by carbon monoxide poisoning through incomplete combustion of coal briquettes. Each member of the group suicide provided information, a room or a car, coal briquettes, sleeping pills etc.

(6) They researched on Lineage, a MMORPG which started its service in 1998 by South Korean company.

(7) Sociological research on social ties between complete strangers or heterogeneous people is not always associated with social media. In recent Japan, some sociologists pay attention to social ties through hobbies. For example, see Asano (2011).

(8) Hidenori Tomita pointed out the merge between real and virtual world under the label of "complex reality society". On this point he mentioned Internet group suicide, off-line meeting, flash mobs and so on (Tomita 2009).

(9) Louis Wirth defined the city as a "Substitution of secondary for primary contacts, the weakening of bonds of kinship, the declining social significance of the family, the disappearance of neighborhood and the undermining of traditional basis of social solidarity" (Wirth 1938).

\section{References}

Asano, Tomohiko, 2011, Shumi-en kara hajimaru shakai sanka (Social participation which starts with hobby connection), Tokyo: Iwanami Shoten.

Boyd, Danah M. and Nicole B. Ellison, 2007 "Social Network Sites: Definition, History, and Scholarship", Journal of Computer-Mediated Communication, 13: 210-230. (http://jcmc. indiana.edu/vol13/issue1/boyd.ellison.html)

Granovetter, Mark, 1973, "The Strength of Weak Ties", American Journal of Sociology, 78(6): 1360-1380.

Granovetter, Mark, 1985, "Economic Action and Social Structure: The Problem of Embeddedness", American Journal of Sociology, 91 (3): 81-510. 
Kobayashi, Tetsuro and Ken'ichi Ikeda, 2005, "Online community no shakai kankei shihon (Social Capital of Online Community)", Ken'ichi Ikeda (ed.), Internet Community and Everyday World (in Japanese), Tokyo: Seishin-Shobo, 148-184.

Luhmann, Niklas, 1982, Liebe als Passion: Zur Codierung von Intimität, Frankfurt am Main: Suhrkamp. ( $=1986$, translated by Jeremy Gaines and Doris L. Jones, Love as Passion: The Codification of Intimacy, Cambridge: Harvard U. P.)

Luhmann, Niklas, 1995, Die Realität der Massenmedien, Opladen: Westdeutscher.

Luhmann, Niklas, 1997, Die Gesellschaft der Gesellschaft, Frankfurt am Main: Suhrkamp. $(=2009$, translated by Yasuo Baba, Saburo Akahori, Ken Sugawara and Toru Takahashi, Shakai no Shakai (Society of Society), Tokyo: Hosei University Press.)

Miyata, Kakuko, 2005, Kizuna wo tsunagu media: Netto jidai no syakai kankei shihon (Kizuna Connecting Media: Social Capital in Internet Era), Tokyo: NTT Press.

NHK-Special crew (ed.), 2012, Muen-Shakai (Disconnected Society), Tokyo: Bungei Shunju.

Putnam, Robert D, 2000, Bowling Alone: The Collapse and Revival of American Community, New York: Simon \& Schuster.

Rheingold, Howard, 1993, The Virtual Community: Homesteading on the Electronic Frontier, Reading, Mass.: Addison-Wesley.

Shibui, Tetsuya, 2004, Netto Shinju (Group Suicide through Internet), Tokyo: NHK Press.

Shimura, Makoto, 2005, "Internet no communication riyou ga kojin ni motarasu kiketsu (Consequence of Communicative Use of Internet to Individuals)", Ken'ichi Ikeda (ed.), Internet Community and Everyday World (in Japanese), Tokyo: Seishin-Shobo, 112-131.

Taylor, Matthew, 2012, "Not with a Bang but a Whimper: Muen Shakai and Its Implications", Anthropoetics - The Journal of Generative Anthropology, 18(1). (http://www.anthropoetics. ucla.edu/ap1801/1801 taylor.htm)

Tomita, Hidenori, 2009, Intimate Stranger (in Japanese), Suita, Osaka: Kansai University Press.

Wirth, Louis, 1938, "Urbanism as a Way of Life”, American Journal of Sociology, 44 (1): 124. 